\title{
Synthesis of Nano-Titanium Tannate as an Adsorbent for Crystal Violet Dye, Kinetic and Equilibrium Isotherm Studies
}

\author{
Taha M. Elmorsi \\ Chemistry Department, Faculty of Science, Al-Azhar University, Cairo, Egypt \\ Email: taha_elmorsi@yahoo.com \\ Received 15 December 2015; accepted 28 December 2015; published 31 December 2015 \\ Copyright (C) 2015 by author and Scientific Research Publishing Inc. \\ This work is licensed under the Creative Commons Attribution International License (CC BY). \\ http://creativecommons.org/licenses/by/4.0/ \\ (c) (i) Open Access
}

\begin{abstract}
The purpose of this study was to prepare nano-titanium tannate complex (TTC) and to investigate its adsorption capacity for removal of cationic dyes such as crystal violet (CV) dye. The morphology and the main elements of TTC adsorbent were characterized by scanning electron microscopy (SEM-EDS), while its crystal structure was characterized by X-ray diffraction (XRD). Also, FT-IR spectroscopy study structural aspects of TTC. A "cotton-ball"-like and porous surface structure of titanium tannate complex (TTC) with nanoparticle size of $16.18 \mathrm{~nm}$ show high capability for absorbing crystal violet dye. The effect of several parameters such as contact time, initial concentrations of CV, solution pH and the amount of TTC was investigated. Three different kinetic equations such as pseudo-first order, pseudo-second order and intraparticle diffusion were used to study the order and the mechanism of the adsorption process. The adsorption of CV dye followed pseudosecond order equation. Moreover, equilibrium data were tested with four adsorption isotherm models namely, Langmuir, Freundlich, Temkin and Dubinin-Radushkevich (D-R). Langmuir was the best fit for the data with maximum capacity as $58.8 \mathrm{mg} / \mathrm{g}$. The results of Separation factor, Surface coverage and standard free energy $\left(\Delta G^{\circ}\right)$ indicated that adsorption of CV onto TTC was favorable with fast rate and spontaneous physical adsorption process.
\end{abstract}

\section{Keywords}

Titanium(III) Tannate Complex (TTC), Crystal Violet, Adsorption Kinetics, Adsorption Isotherms

\section{Introduction}

Due to the rapid growth of the need for water in different industries, huge number of different pollutants accumulated in water. In many cases, these pollutants make water unsuitable to be reused and become wastewater [1]. 
Presence of these pollutants in water such as organic dyes and heavy metals became a major concern not only for the human health but for the entire environment quality [2] [3]. In addition, water polluted with low concentration of organic dyes [4] [5] or even trace levels of heavy metals can cause serious health problems to human body [6]. Hence, there is an urgent need for water treatment using different techniques. Currently, several processes such as chemical, biological and/or physical processes [7]-[12] have been used for the treatment of different pollutants. Physical processes such as adsorption method are a unique technique used for accumulating the pollutant molecules onto the surface of the adsorbent to remove it from the aqueous or organic phase. Adsorption is not only a least complex technique but it is cheap and effective method for removal of different pollutants [13] [14]. Although activated carbon is the effective adsorbent used in adsorption method, its production is highly coast [15] and requires complex care [16]. Production of an alternative effective adsorbent which does not require many processing is of great interest. There are many low-coast adsorbents (also called green adsorption), used for removal of different pollutants [16]. However, the adsorption capacity of many of them is not large [17]. Therefore, other adsorbents with better adsorption capacities and good performance are still under development [17]. It is known that several industries including textiles, plastics and printing use different dyes such as cationic, anionic and non-ionic dyes for coloring [18]. Cationic dyes were used extensively due to their good characteristics such as low coast production, solubility, bright color and applying to fabric. It was reported that from $0 \%$ to $5 \%$ of the produced cationic dyes were released directly to the wastewater [19]. Crystal violet (CV) a type of a synthetic basic triphenylmethane dyes which can exist in the form of colored cations [20]. CV is mainly used in textile and medicine industries [21]. Aqueous effluents of CV are toxic and may absorb through skin causing different health problems [15] [22]. CV was chosen as a pollutant model to evaluate the efficiency of the studied adsorbent. To the best of our knowledge, the research of R. Zhang et al., [23] was the only work on an optimized method for synthesizing ferric tannate complex by using tannic acid. However, no work has been done to synthesis titanium(III) tannate complex (TTC) by using tannic acid and Ti(III) chloride. In this study, we reported the synthesis and characterization of titanium(III)-tannate complex (TTC) in addition to investigating its adsorption capacity for adsorption of cationic dyes such as CV dye. Several parameters were investigated such as adsorbent dosage, contact time, initial CV dye concentration and temperature. In addition, adsorption isotherm kinetics of the adsorption process were studied.

\section{Experiment}

\subsection{Chemicals}

Analytical-grad that chemicals were used in this work without further purification. Crystal violet, a type of triphenylmethane dyes with molecular formula (C25H30ClN3), (aq. solubility $16 \mathrm{~g} / \mathrm{l}$; purity 80\%) as shown in Figure 1 was received from LOBA Chemie Company, India and used as received. To evaluate the significant of the adsorbent, stock solutions $(1000 \mathrm{mg} / \mathrm{L})$ of CV was prepared in double distilled water and further diluted to perform adsorption experiments in presence of titanium(III)-tannate complex (TTC) as an adsorbent. Dilute solutions of $1 \mathrm{M} \mathrm{HNO}_{3}$ and $1 \mathrm{M} \mathrm{NaOH}(\mathrm{BDH})$ were used to adjust $\mathrm{pH}$ of $\mathrm{CV}$ solutions using a $\mathrm{pH}$ meter.

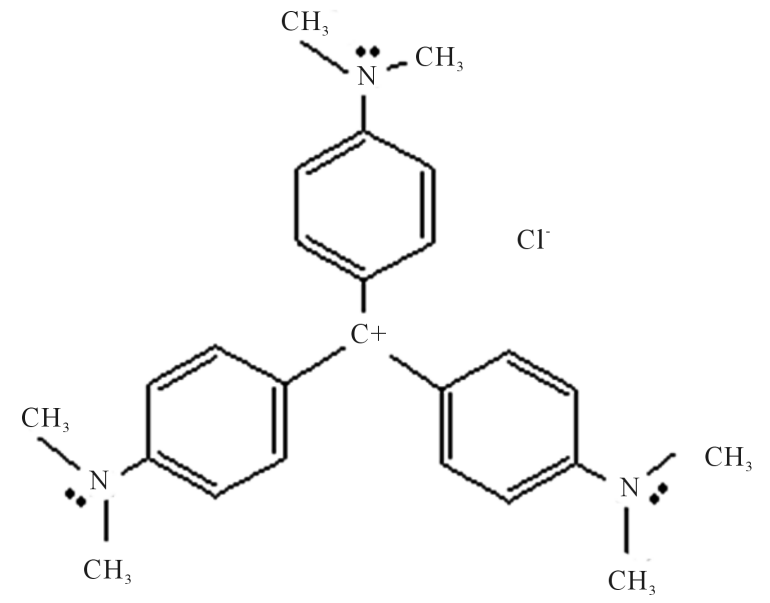

Figure 1. Crystal violet structure (mol. formula $\mathrm{C}_{25} \mathrm{H}_{30} \mathrm{ClN}_{3}$ ). 


\subsection{Synthesis of Titanium(III) Tannate Complex (Adsorbent)}

A Beaker with an amount of $50 \mathrm{ml}$ (4\%:1.0\%, ethanol: water) of tannic acid (0.1 M) was placed in ultrasonic bath and sonicated for few minutes. Then a cretin volume of $\mathrm{TiCl}_{3}$ was added drop wise with continuous sonication for 8.0 minutes. The molar ratio of tannic acid to titanium(III) chloride was chosen to be 1:20 according to R. Zhang et al., [23]. The $\mathrm{pH}$ of the mixture was adjusted to $3.5-4.0$ using tris-HCl to avoid precipitation of titanium ion in the form of hydroxide. The colorless solution of tannic acid turned to orange precipitate at the beginning of the addition of titanium(III) chloride then changed into dark red precipitate. Complete precipitation was tested by adding few drops of both tannic acid solution and titanium ion solution respectively. There was no more precipitate formed to indicate that the chosen molar ratio of tannic acid to titanium(III) chloride was optimal. The obtained product was separated through precipitation and washed several times with $30 \%: 70 \%$ ethanol: water then dried in the oven overnight at $60^{\circ} \mathrm{C}$ before use in the adsorption experiments.

\subsection{Characterization of Titanium(III) Tannate}

To study the surface morphology and main elements present in the complex of titanium tannate, scanning electron microscopy (SEM) using SEM model Quanta 250 FEG attached with an energy dispersive X-ray spectroscopy (EDS) unit with accelerating voltage $30 \mathrm{~K} . \mathrm{V}$., magnification $14 \mathrm{x}$ up to 1000,000 and resolution for Gun.1n was used. The crystal structure of titanium tannate was analyzed by X-ray diffraction (XRD) in scan mode with $\mathrm{Cu}-\mathrm{Ka}$ radiation $(\lambda=0.01542 \mathrm{~nm})$ in the $2 \theta$ range of $10^{\circ}$ to $80^{\circ}$. The functional group in the synthesized complex was analyzed through the analysis of Fourier transform infrared spectrometry (FTIR) using KBr pellet in the range of 400 to $4000 \mathrm{~cm}^{-1}$.

\subsection{Adsorption Experiments}

To evaluate the significant of titanium(III) tannate complex (TTC) as an adsorbent, CV dye solution was used in this study as an environmental pollutants. Stock solutions $(1000 \mathrm{mg} / \mathrm{L})$ of $\mathrm{CV}$ was prepared in distilled water and further diluted to the required concentration to perform the calibration curves and adsorption experiments. Serial dilutions (1.0 to $6.0 \mathrm{mg} / \mathrm{L}$ ) of CV stock solutions were used to prepare the calibration curves. Batch adsorption experiments were performed by introducing known amounts of TTC into several glass tubes, each containing $5.0 \mathrm{~mL}$ (to minimize the waste) of $\mathrm{CV}$ solution with an initial concentration ranging from 40 to 150 $\mathrm{mg} / \mathrm{L}$. Tubes were agitated at $120 \mathrm{rpm}$ using an electric shaker at room temperature. To ensure performing the adsorption experiments at known $\mathrm{pH}$ value, the $\mathrm{pH}$ was adjusted before starting the experiment using solution of either $\mathrm{NaOH}$ or $\mathrm{HCl}$. At interval times, $\mathrm{CV}$ solutions were withdrawn and introduced into a centrifuge to separate TTC powder from samples. CV solutions of $50 \mathrm{mg} / \mathrm{L}$ with different amount of TTC powder $(0.5$ to $2.5 \mathrm{~g} / \mathrm{L})$ were used to study the effect of adsorbent dose on the adsorption process. The effect of $\mathrm{pH}$ was studied by performing similar experiments with $2.0 \mathrm{~g} / \mathrm{L}$ of TTC powder at different pHs from 2.75 to 10 . A known amount of TTC powder ( $2.0 \mathrm{~g} / \mathrm{L}$ ) were added to $5.0 \mathrm{~mL}$ of CV solution with different concentrations (40 to $150 \mathrm{mg} / \mathrm{L}$ ) at room temperature to calculate the adsorption isotherm.

\subsection{Analytical Methods}

UV-vis spectrophotometer (Perkin Elmer) was used to determine the concentrations of CV solution before and after the adsorption experiments. Calibration curves were obtained and used to calculate dye concentrations during adsorption experiments at any time $\left(C_{t}\right)$.

The amount of CV dye sorbed onto TTC powder at any time, $q_{t}$ (mg/g), was calculated from;

$$
q_{t}=\frac{V\left(C_{0}-C_{t}\right)}{W}
$$

At equilibrium, $q_{t}=q_{e}$ and $C_{t}=C_{e}$; therefore the amount of sorbed CV dye, $q_{e}$, was calculated from

$$
q_{e}=\frac{V\left(C_{0}-C_{e}\right)}{W}
$$

where $C_{0}, C_{t}$ and $C_{e}$ are the initial concentration, concentration at any time and equilibrium concentrations of CV dye solution (mg/L), respectively, $V$ is the volume of the dye solution (L), and $W$ is the mass of TTC (g). 
Dye removal percentage can be calculated as follows:

$$
\text { Removal\% }=\frac{\left(C_{0}-C_{t}\right)}{C_{0}} \times 100
$$

\subsection{Adsorption Kinetics}

Kinetic Study will allow the determination of the rate of CV uptake by TTC adsorbent which in turn led to measuring the efficiency of the adsorption process. Three different kinetic models namely a pseudo-first order [24]-[26], a pseudo-second order [27] [28] and an intraparticle diffusion [29] were used in the current study. The linear form of Lagergren pseudo-first order model is represented as:

$$
\log \left(q_{e}-q_{t}\right)=\log q_{e}-\left(\frac{k_{1}}{2.303}\right) t
$$

where $q_{e}$ and $q_{t}$ are the amounts of the CV adsorbed (mg/g) at equilibrium and at time $t$ (min), respectively, and $k_{1}$ is the rate constant of adsorption $\left(\mathrm{min}^{-1}\right)$.

While, the linear form of pseudo second-order developed by Ho [27] based on equilibrium adsorption can be expressed as:

$$
\frac{t}{q_{t}}=\frac{1}{k_{2} x q_{e}^{2}}+\left(\frac{1}{q_{e}}\right) t
$$

where $k_{2}$ (g/mg-min) is the adsorption rate constant of pseudo second-order adsorption rate.

Also, intraparticle diffusion equation can be described by the following equation:

$$
q_{t}=k_{i d} \sqrt{t}+C
$$

where, $k_{i d}$ the intraparticle diffusion rate constant $\left(\mathrm{mg} / \mathrm{g} \cdot \mathrm{min}^{-1 / 2}\right)$ and $C$ is the intraparticle diffusion constant (mg.g ${ }^{-1}$ ). The plot of $q_{t}$ versus $t^{1 / 2}$ is used to calculate the constants $k_{i d}$ and $C$ from the slope and the intercept respectively. The relative values of $C$ give an idea about the boundary layer thickness, i.e., the larger the intercept value, the greater the boundary layer effect [22].

\subsection{Adsorption Isotherm}

The equilibrium state between the amount of adsorbed onto the adsorbent surface $\left(q_{e}\right)$ and the concentration of adsorbate in solution $\left(C_{e}\right)$ at a fixed both temperature and $\mathrm{pH}$ is described by adsorption isotherm. In this study, linear forms of four different adsorption isotherm equations were used to describe the equilibrium data. These equations are Langmuir [30] [31] and Freundlich [32] in addition to Temkin [33] [34] and Dubinin-Radushkevich (D-R) equation [35] [36]. The parameters of those equations can describe both the surface properties and the affinity of the adsorbent such as TTC to the adsorbate such as CV dye. Also, adsorption maximum capacity, adsorption intensity and the heat of adsorption $(\mathrm{kJ} / \mathrm{mol})$ which indicates the adsorption potential can be measured.

\section{Results and Discussion}

\subsection{Characterization of Titanium(III) Tannate}

SEM images of the morphology of the synthesized titanium tannate complex (TTC) is shown in Figure 2 at two different magnification view as low $(30,000 \times)$ and high $(100,000 \times)$. The images show bladed crystals for TTC with "cotton-ball”-like morphology and porous surface structure. In addition, the average particle size was estimated from SEM image (Figure 2(b)) as $16.18 \mathrm{~nm}$. The main elements present in TTC is determined by SEMEDS spectrum and shown in Figure 3. The results indicated that the carbon, oxygen, titanium were the main elements present in TTC structure with percent composition as $21.07 \%, 48.95 \%$ and $28.75 \%$ by weight respectively. The calculated percent composition from the SEM-EDS spectrum shows that the ratio of carbon to oxygen is different from their ratio in the chemical formula of tannic acid (C76H52O46). Although previous research [23] proposes a possibility of hydrolysis of metal ions such as Ti(III) which led to increase the \% of oxygen, further research is required to prove that. Figure 4 shows the XRD patterns of $16.18 \mathrm{~nm}$ TTC with a diffraction peaks appear in the range of $2 \theta=30^{\circ}$ to $35^{\circ}$ indicated that titanium tannate complex has an amorphous structure. 

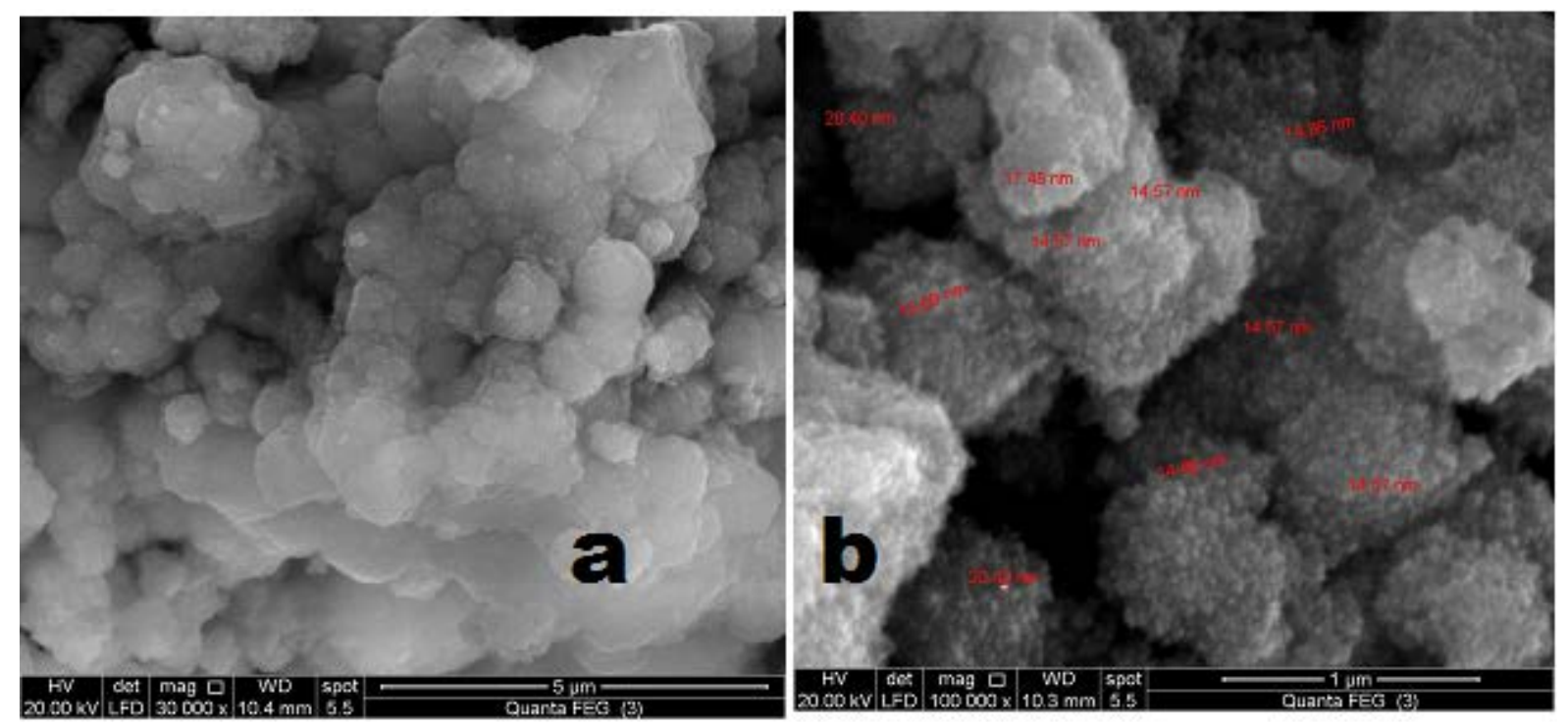

Figure 2. (a) Low $(30,000 \times)$ and (b) high $(100,000 \times)$ magnification SEM images of TTC.

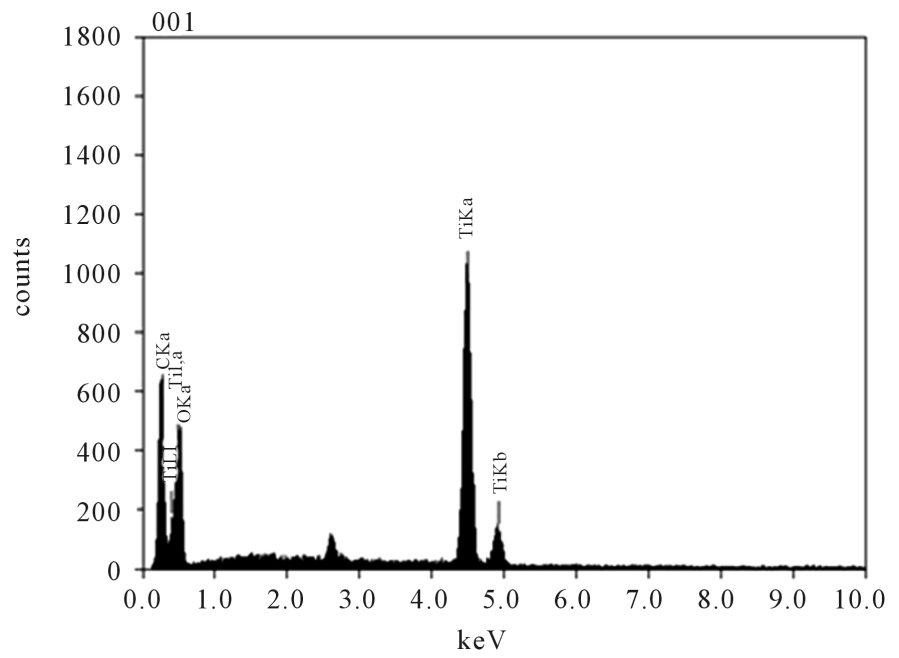

Figure 3. SEM-EDS spectrum of TTC.

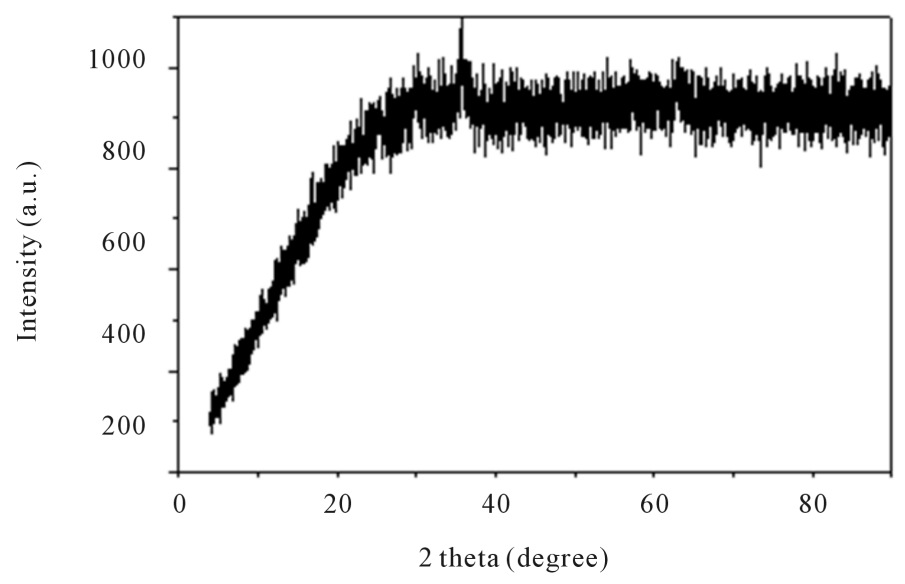

Figure 4. XRD spectra of the titanium tannate complex. 
The results in Figure 5 show the FTIR spectra of tannic acid (TA) and titanium tannate complex (TTC). The results show that the main bands appeared in the spectrum of tannic acid are the stretching vibrations band of hydroxyl group (OH) of the phenolic ring which appeared as abroad band at $3700 \mathrm{~cm}^{-1}$ to $3000 \mathrm{~cm}^{-1}$ range due to the hydrogen bonding between $\mathrm{OH}$. Also, stretching vibration carbonyl groups $(\mathrm{C}=\mathrm{O})$ appeared at 1730 $1705 \mathrm{~cm}^{-1}$, in addition to C-O bands at $1100-1300 \mathrm{~cm}^{-1}$ as reported also previously [23] [37]. For FTIR spectra of TTC (solid line in Figure 5), the major difference was in the OH group region in addition to the C-O region where absorption was much less indicating that the $\mathrm{C}-\mathrm{O}$ bonds had been weakened as would occur when chelated with titanium ion. Bonding therefore occurred between the metal ion and the hydroxyl groups. Accordingly, the suggested structure of titanium tannate complex is shown in Figure 6.

\subsection{Effect of Contact Time and Initial Concentrations of CV Dye}

A known amount of ttc powder $0.010 \mathrm{~g}(2.0 \mathrm{~g} / \mathrm{L})$ was added to $0.005 \mathrm{~L}$ of different concentrations of CV (from $40-150 \mathrm{mg} / \mathrm{L}$ ). For a total period of $120 \mathrm{~min}$ at a temperature of $298 \mathrm{~K}$, experiments were performed to evaluate the effect of contact time $(0-120 \mathrm{~min})$ and different initial concentrations $(40,50,70,90$ and $150 \mathrm{mg} / \mathrm{L})$ of $\mathrm{CV}$ dye on the adsorption process as shown in Figure 7. The obtained results in indicated that the curve of the adsorption rate of CV onto TTC powder was very rapid in the first 10 min confirming the presence of large number of readily accessible adsorption sites. For example at $40 \mathrm{mg} / \mathrm{L}$ of CV the adsorbed amount $\left(q_{t}\right)$ reached

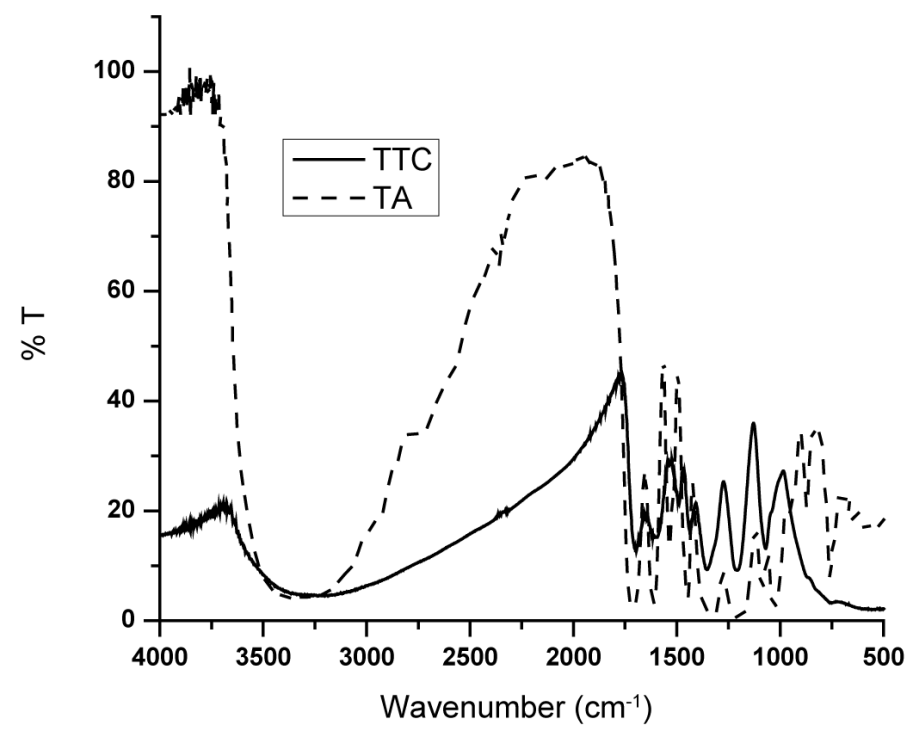

Figure 5. FTIR of tannic acid (TA) and titanium tannate complex (TTC).

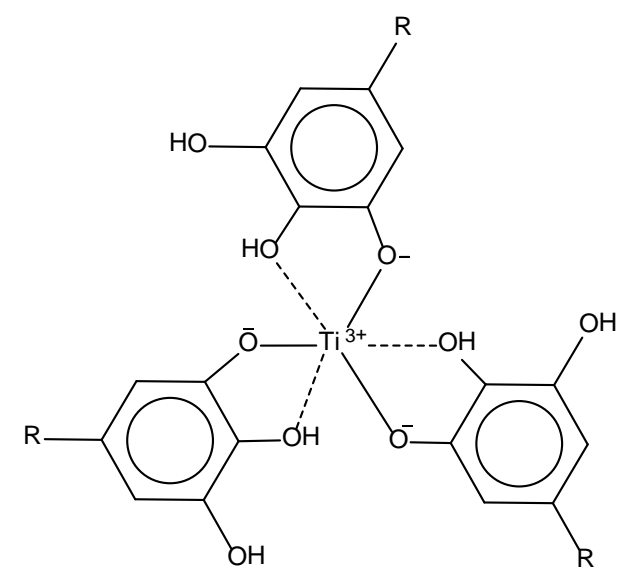

Figure 6. Suggested chemical structure of titanium tannate complex. 


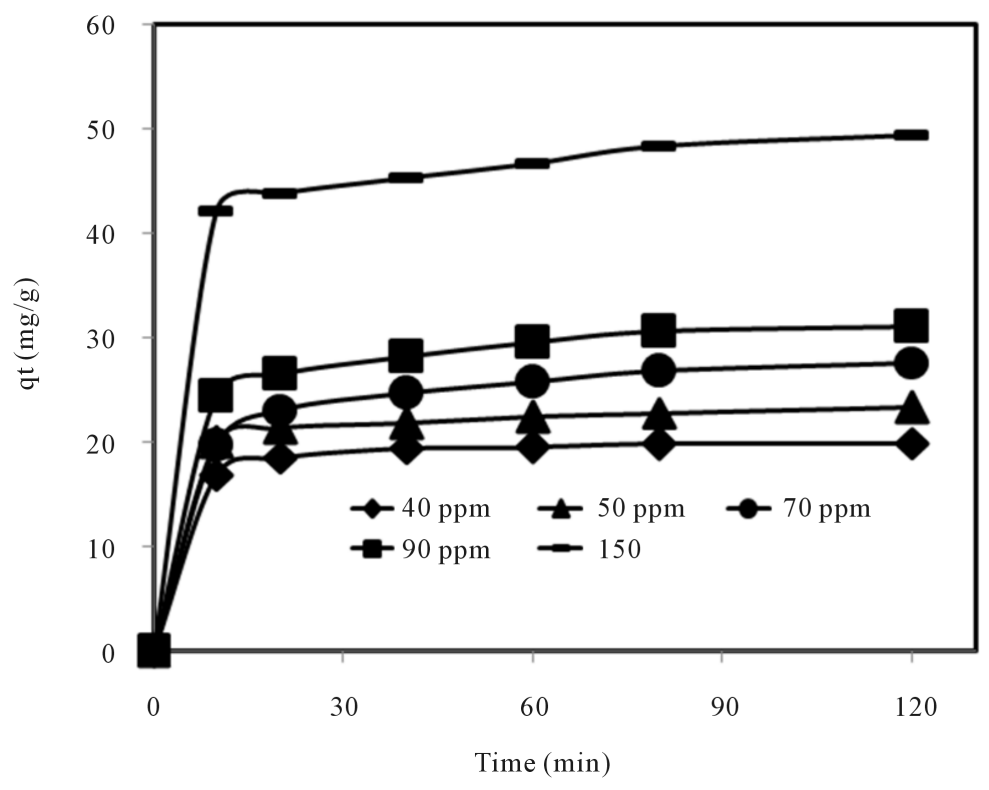

Figure 7. Effect of initial concentrations and contact time on the adsorption of crystal violet dye onto TTC powder $(\mathrm{T}=298 \mathrm{~K}$, time $=120 \mathrm{~min}$, [CV]0 = $40-150 \mathrm{mg} / \mathrm{L}, \mathrm{pHi}=7, \mathrm{~V}=0.005 \mathrm{~L}$, TTC dosage $=2.0 \mathrm{~g} / \mathrm{L})$.

$16.85 \mathrm{mg} / \mathrm{g}$, which represented about 78.11\%, comparing to $19.91 \mathrm{mg} / \mathrm{g}$ (92.3\%) at $120 \mathrm{~min}$. Then, the adsorption of CV dye increased gradually during the following $40 \mathrm{~min}$ until reached equilibrium at about $120 \mathrm{~min}$. Furthermore, the sorbed amount of CV dye was also increased from 16.85 to $42.10 \mathrm{mg} / \mathrm{g}$ by increasing the initial concentrations from 40 to $150 \mathrm{mg} / \mathrm{L}$ respectively. The results showed that the uptake of CV dye by TTC powder depends on the contact time and the initial concentration. This may be due to the time required for the CV dye to encounter the boundary layer effect, then diffuse to the surface of TTC powder and finally diffuse to the porous structure [38]. Also, it was noted that the time profile of the adsorption of CV dye reached saturation in a single, smooth and contentious curve which indicated the possible formation of monolayer of CV dye onto the surface of TTC powder [39]. To ensure complete equilibrium of the data, adsorption samples were collected at 120 min.

\subsection{Effect of Solution $\mathrm{pH}$ on Adsorption of CV}

Adsorption rate can be affected by the degree of ionization of adsorbate and the surface charge of adsorbent [40]-[42]. However, these two parameters were controlled mainly by the initial solution $\mathrm{pH}$. To evaluate the effect of $\mathrm{pH}$ on the equilibrium adsorption capacity $\left(q_{e}\right)$ of CV onto TTC surface, experiments were conducted at $50 \mathrm{mg} / \mathrm{L}[\mathrm{CV}]_{0}, 2.0 \mathrm{~g} / \mathrm{L}$ TTC dose, and $120 \mathrm{~min}$ contact time at a temperature of $298 \mathrm{~K}$. Figure 8 indicated that the adsorption rate was slow in acidic medium at $\mathrm{pH} 2.75$ with $64.46 \%$ removal. Then the \% removal continue to be linearly proportional to the increase in the initial $\mathrm{pH}$ values until reached maximum removal of $94.33 \%$ in basic medium when the $\mathrm{pH}$ values increases from 8 to 10. It is known that crystal violet dye gives positively charged ion (colored cation) which can compete with $\mathrm{H}^{+}$ions in solution at high $\mathrm{pH}$ value for the adsorption sites and lead to decrease the adsorption rate. Thus when the $\mathrm{pH}$ value of the solution increased from 2.75 to 7 lead to decrease the competition between $\mathrm{H}^{+}$ions and cationic $\mathrm{CV}$ dye in solution and thus led to increase the adsorption rate. Moreover, increase the negative charge on the surface of TTC due to increase the concentration of OH-ions in basic medium, led to increase the electrostatic attraction of positively charged CV dye and increases the adsorption process [43]. Similar results were observed for our previous research on the adsorption of methylene blue dye, a cationic dye (MB dye ${ }^{+}$) onto miswak leaves [44]. In addition, the adsorption of crystal violet onto different adsorbents such as activated carbons derived from male flowers of coconut tree [28], tobacco stem [32] and some metal cations onto different adsorbents such as Cd(II) ion onto activated red mud [45] was previously reported with similar trend. These results on effect of $\mathrm{pH}$ indicate that the solution $\mathrm{pH}$ controls the electrostatic interactions between adsorbent surface and adsorbate in the solution which can have a profound effect on the adsorption process. 


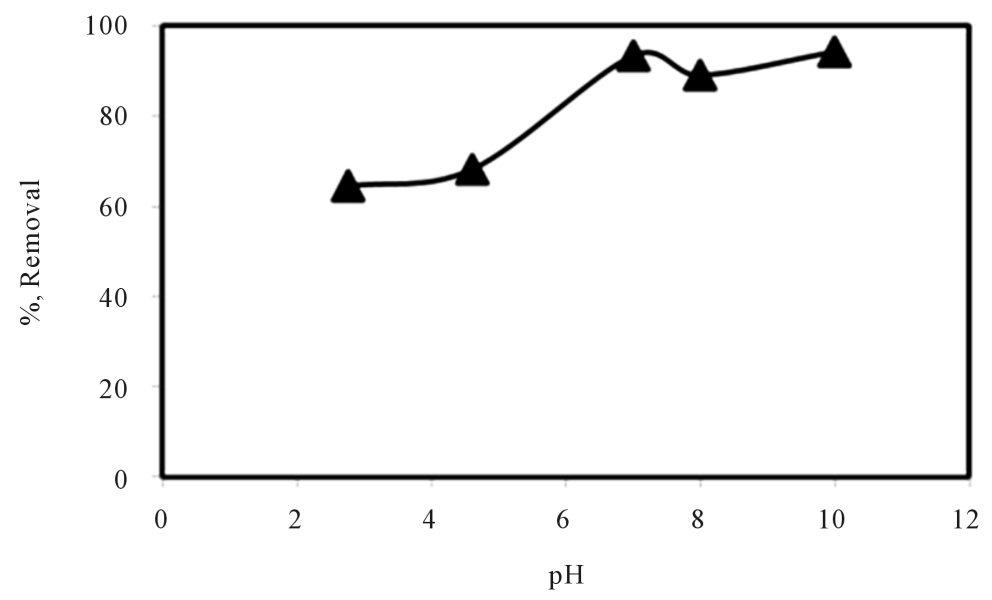

Figure 8. Effect of solution $\mathrm{pH}$ on the adsorption of crystal violet dye onto TTC $(\mathrm{T}=298 \mathrm{~K}$, time $=120 \mathrm{~min},[\mathrm{CV}] 0=50 \mathrm{mg} / \mathrm{L}, \mathrm{V}=0.005 \mathrm{~L}$, TTC dosage $=2.0 \mathrm{~g} / \mathrm{L})$.

\subsection{Effect of Adsorbed Amount}

To investigate the effect of adsorbent dosage on the adsorption of CV, different tubes filled with a specific volume of CV dye solution with [CV]0 (50 mg/L) at different amounts of TTC powder $(0.25$ to $2.5 \mathrm{~g} / \mathrm{L})$ at room temperature. Figure 9 showed a general trend for the adsorption of CV onto the surface of TTC. The percent removal of CV increased rapidly in the first stage with the increase in the adsorbent dose then increased slowly until reached equilibrium with the further increase in the adsorbent dose. The solution of CV dye is decolorized by $31.63 \%$ by using $0.5 \mathrm{~g} / \mathrm{L}$ of TTC dosage. The decolonization rate of CV solution increases dramatically by introducing more dosage of TTC to reach $96.27 \%$ at dosage of $2.0 \mathrm{~g} / \mathrm{L}$ TTC. Furthermore, increasing the dosage of TTC to $2.5 \mathrm{~g} / \mathrm{L}$ leads to decrease the \% removal to reach $92.95 \%$. Thus in further experiments $2.0 \mathrm{~g} / \mathrm{L}$ of TTC were chosen as the optimum dose. It is clear that the increase in both the surface area and the adsorption sites which resulted by introducing more dosage of TTC adsorbent, lead to increase the \% removal of CV from aqueous solution. On the other hand, \% removal of CV decreased from $96.27 \%$ to $92.95 \%$ when introducing more amount of TTC as $2.5 \mathrm{~g} / \mathrm{L}$. It was reported that [46] increasing the amount of the adsorbent may led to increase the overlapping and/or aggregation of the adsorption sites on the adsorbent surface which can decrease the adsorption rate.

\subsection{Adsorption Kinetics (Determining Adsorption Rate Constant)}

Determining the kinetic parameter (such as the rate constant) and predicting information about adsorbent/adsorbate interaction it is significant for any adsorption experiments. As discussed above, three different models were used to study the kinetic of adsorption of CV onto TTC powder.

\subsubsection{Pseudo First-Order Equation}

Equation (4) expressed the linear form of Langergren pseudo first-order for the adsorption process of CV dye onto TTC adsorbent. Different concentrations of CV dye $(40-150 \mathrm{mg} / \mathrm{L})$ were used to calculate $k_{1}$ and $q_{e}$ from the slope and the intercept of the plots of $\log \left(q_{e}-q_{t}\right)$ versus $t$ as shown in Figure 10(a). The value of $k 1$ and $q_{e}$ determined from Equation (4) are presented in Table 1 along with the corresponding correlation coefficients $\left(R^{2}\right)$. The low values of $R^{2}$ and the disagreement between the experimental and the calculated values of $q_{e}$ indicated that the adsorption of CV dye onto TTC is not first-order kinetics.

\subsubsection{Pseudo-Second Order Rate Equation}

The kinetic data of the adsorption of CV onto TTC were further analyzed by the linear form of pseudo-second order model (Equation (5)). The slope and the intercept of the plot of $\frac{t}{q_{t}}$ versus $t$ is used to determine the value 


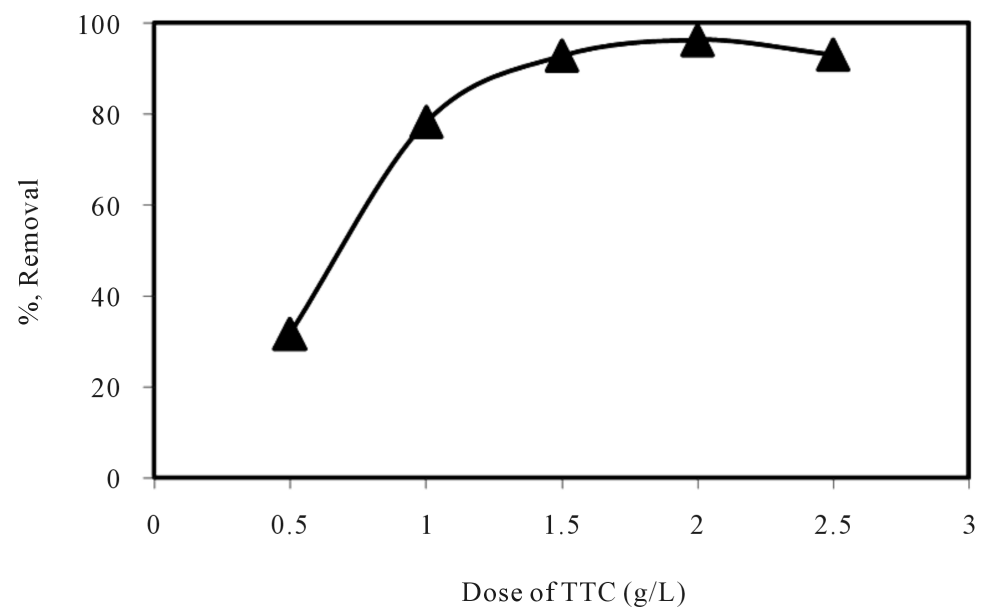

Figure 9. Effect of adsorbent dose on the adsorption of crystal violet onto TTC $(\mathrm{T}=298 \mathrm{~K}$, time $=120 \mathrm{~min},[\mathrm{CV}] 0=50 \mathrm{mg} / \mathrm{L}, \mathrm{pHi}=7, \mathrm{~V}=0.005 \mathrm{~L}$, ttc dosage $=0.5 .0-2.5 \mathrm{~g} / \mathrm{L})$.

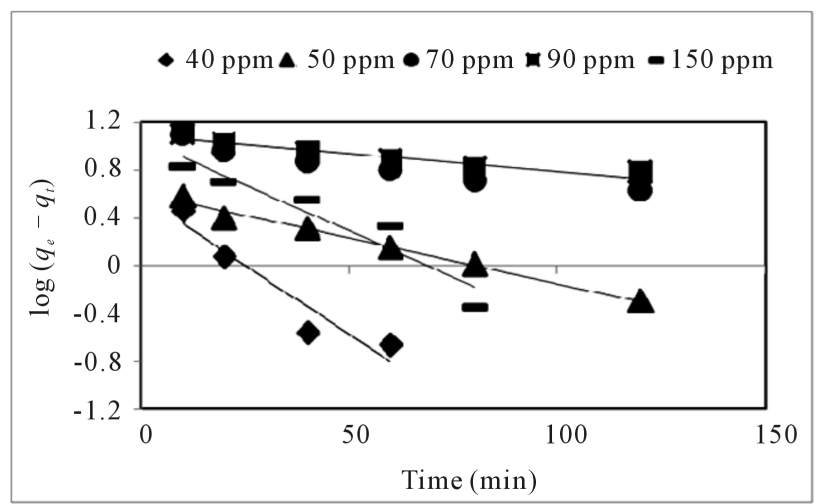

(a)

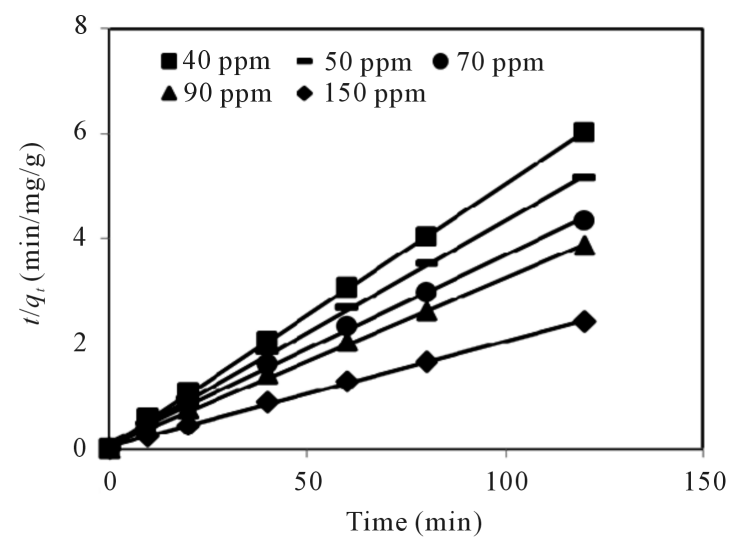

(b)

Figure 10. Pseudo-first order (a) and Pseudo-second order (b) kinetics for the adsorption of CV onto TTC $(\mathrm{T}=298 \mathrm{~K}$, time $=$ $120 \mathrm{~min},[\mathrm{CV}] 0=40-150 \mathrm{mg} / \mathrm{L}, \mathrm{pHi}=7, \mathrm{~V}=0.005 \mathrm{~L}$, TTC dosage $=2.0 \mathrm{~g} / \mathrm{L})$.

Table 1. Adsorption kinetic parameters for the adsorption of CV onto TTC $(\mathrm{T}=298 \mathrm{~K}$, time $=120 \mathrm{~min}$, [CV]0 $=40-150$ $\mathrm{mg} / \mathrm{L}, \mathrm{pHi}=7, \mathrm{~V}=0.005 \mathrm{~L}$, TTC dosage $=2.0 \mathrm{~g} / \mathrm{L}$ ).

\begin{tabular}{cccccccc}
\hline & \multicolumn{3}{c}{ First-order kinetic model } \\
\hline $\begin{array}{c}{[\mathrm{CV}] 0} \\
(\mathrm{mg} / \mathrm{L})\end{array}$ & $\begin{array}{c}q_{e}, \text { exp } \\
(\mathrm{mg} / \mathrm{g})\end{array}$ & $\begin{array}{c}q_{e}, \mathrm{cal} \\
(\mathrm{mg} / \mathrm{g})\end{array}$ & $\begin{array}{c}\mathrm{k} 1 \\
\left(\mathrm{~min}^{-1}\right)\end{array}$ & $\mathrm{R} 2$ & $\begin{array}{c}q_{e}, \mathrm{cal} \\
(\mathrm{mg} / \mathrm{g})\end{array}$ & $\begin{array}{c}\mathrm{k} 2 \\
\left(\mathrm{~g} / \mathrm{mg}^{\mathrm{m}} \mathrm{min}^{-1}\right)\end{array}$ & $\mathrm{R} 2$ \\
\hline 40 & 20.060 & 5.370 & 0.035 & 0.807 & 20.41 & 0.040 & 0.999 \\
50 & 23.417 & 4.498 & 0.025 & 0.974 & 23.81 & 0.025 & 0.999 \\
70 & 30.671 & 11.117 & 0.012 & 0.947 & 28.57 & 0.010 & 0.997 \\
90 & 36.922 & 10.188 & 0.009 & 0.934 & 32.26 & 0.011 & 0.998 \\
100 & 51.502 & 0.012 & 0.012 & 0.988 & 50.00 & 0.010 & 0.998 \\
\hline
\end{tabular}

of both $q_{e}$ and $k_{2}$ respectively. Table 1 presented both values of $k_{1}$ and $q_{e}$ along with the value of $R^{2}$. The results in Figure 10(b) show linear plots with very high values of $R^{2}$ (very close to unity) in addition to a good agreement between experimental and calculated values of $q_{e}$ (Table 1). It is clearly indicated that the 
adsorption of CV dye onto TTC is greatly represented by the pseudo second-order kinetics which means the adsorption process may be chemisorption. Similar trends were shown for the adsorption of CV onto Zeolites from Coal Fly and Bottom Ashes [22]. It is known that one of the advantages of using the second-order equation is that there is no need to know the value of $q_{e}$ from the experiments, as it can be calculated from the slope of its equation. Furthermore, second-order model allows to obtain the initial adsorption rate [47].

\subsubsection{Intra-Particle Diffusion Study}

It is proposed that the uptake of the adsorbate (such as CV dye) by the adsorbent (such as TTC) varies almost proportionately with the square root of the contact time $\left(t^{1 / 2}\right)$ according to the Equation (6) [13]. In order to investigate the mechanism of CV dye adsorption onto TTC, intra-particle diffusion based mechanism was studied. The results indicated that the plot in Figure 11 was not linear over the whole time range. Also, the plot indicated that the external surface adsorption (stage 1) is absent and it is finished before $10 \mathrm{~min}$. Then after $10 \mathrm{~min}$, the intra-particle diffusion control (stage 2) started and kept on to $60 \mathrm{~min}$. Finally, the equilibrium step (stage 3) appeared after $60 \mathrm{~min}$ up to $120 \mathrm{~min}$. It can be seen that the adsorption of CV dye onto TTC involved more than one process, and the intra-particle transport is not the rate-limiting step.

\subsection{Adsorption Isotherms for Crystal Violet}

The affinity of TTC adsorbent for the adsorption of CV dye was evaluated by using different adsorption isotherms such as Langmuir, Freundlich, Temkin and Dubinin-Radushkevich (D-R).

\subsubsection{Langmuir Isotherm}

The Langmuir isotherm model assumes that a monolayer of adsorbed material (in liquid, such as CV is adsorbed over a uniform adsorbent surface such as TTC. The Langmuir-I equation is derived by some mathematical manipulation as:

$$
q_{e}=\frac{q_{m} K_{L} C_{e}}{1+K_{L} C_{e}}
$$

where $q_{m}$ (the maximum capacity of adsorption, $\mathrm{mg} / \mathrm{g}$,) and $K_{L}$ (a constant related to the affinity of the binding sites, $\mathrm{L} / \mathrm{mg}$,) are the Langmuir isotherm constants. Both $q_{m}$ and $K_{L}$ can be determined from the linear form of Langmuir-I equation as:

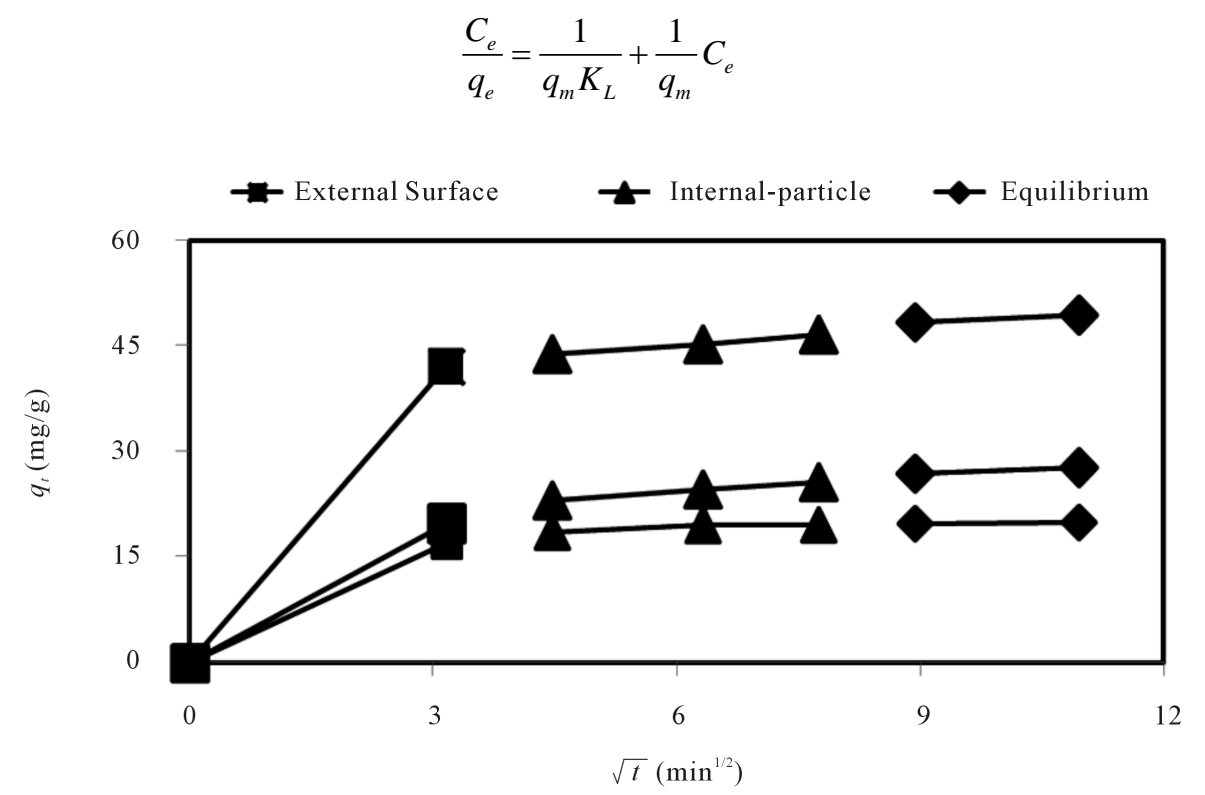

Figure 11. Intra-particle diffusion plot for the adsorption of CV onto TTC $(\mathrm{T}=298 \mathrm{~K}$, time $=$ $120 \mathrm{~min},[\mathrm{CV}] 0=40,70$ and $150 \mathrm{mg} / \mathrm{L}$ (from bottom to top respectively), $\mathrm{pHi}=7, \mathrm{~V}=0.005 \mathrm{~L}$, TTC dosage $=2.0 \mathrm{~g} / \mathrm{L}$ ). 
Figure 12(a) shows the linear fit of Langmuir-I for the adsorption of CV onto TTC at room temperature. The value of $q_{m}, K_{L}$ and $R^{2}$ are presented in Table 2. The high value of $R^{2}$ as 0.999 indicated minimal deviation from the fitted equation showing that the adsorption data would follow Langmuir-I equation. Also, the data in Table 2 indicated that the maximum adsorption capacity of TTC for CV was calculated as $58.8 \mathrm{mg} / \mathrm{g}$. Furthermore, the value of $K_{L}$ gives indication for the affinity between the adsorbent surface (TTC) and the adsorbate (CV dye molecules). It can be mentioned that the surface of TTC is homogeneous and the adsorption of CV dye formed a monolayer on its outer surface hence Langmuir model supposes that the surface of the adsorbent is energetically homogeneous [4] [24]. The adsorption of crystal violet dye also followed Langmuir-I model onto different adsorbents such as zeolites from coal fly ash (ZFA), bottom ash (ZBA) [4] and onto activated carbon derived from Gölbaşı lignite [48]. In addition, S. Patil et al. [48] also, found the adsorption of crystal violet dye onto different adsorbents followed Langmuir-I model and formed monolayer. On the other hand, comparison of maximum monolayer adsorption capacity $\left(q_{m}\right)$ of $\mathrm{CV}$ dye onto various adsorbents obtained in the literature is presented in Table 3 in order to compare the efficiency of TTC adsorbent. It can be seen that TTC is very effective adsorbent for CV dye with a relatively large adsorption capacity of $58.8 \mathrm{mg} / \mathrm{g}$ when compared with some other adsorbents.

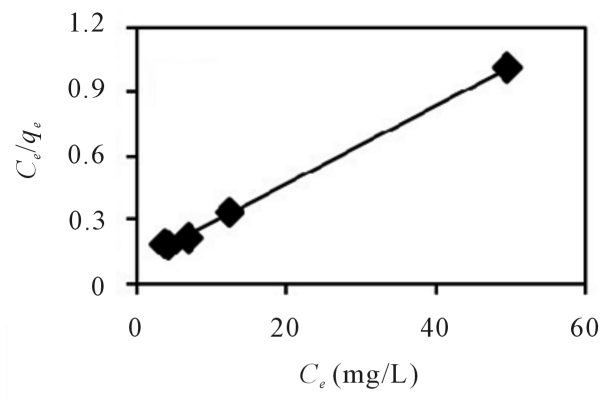

(a)

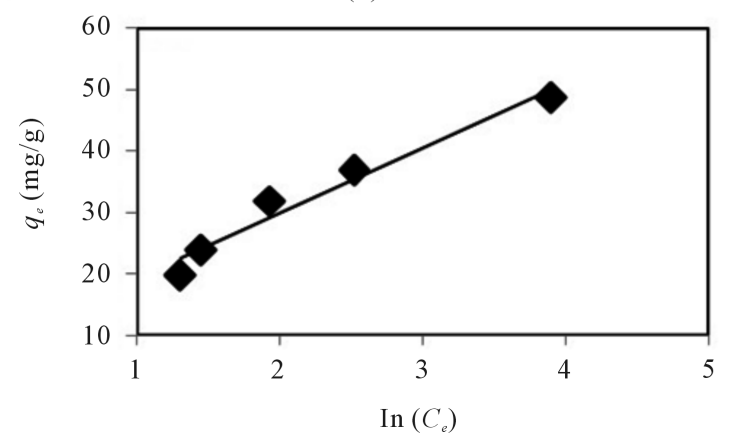

(c)

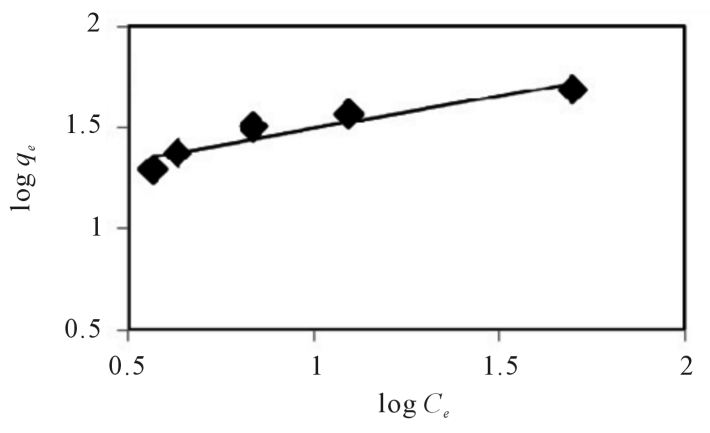

(b)

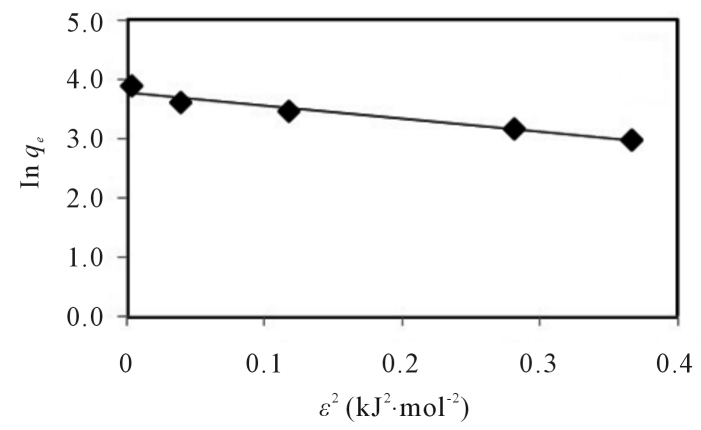

(d)

Figure 12. Adsorption isotherm models, (a) Langmuir-I, (b) Freundlich, (c) Temkin and (d) D-R for the adsorption of CV onto TTC $(\mathrm{T}=298 \mathrm{~K}$, time $=120 \mathrm{~min},[\mathrm{CV}] 0=40-150 \mathrm{mg} / \mathrm{L}, \mathrm{pHi}=7, \mathrm{~V}=0.005 \mathrm{~L}$, TTC dosage $=2.0 \mathrm{~g} / \mathrm{L})$.

Table 2. Langmuir, Freundlich, Temkin and D-R constants for the adsorption of CV onto TTC $(\mathrm{T}=298 \mathrm{~K}$, time $=120 \mathrm{~min}$, $[\mathrm{CV}] 0=40-100 \mathrm{mg} / \mathrm{L}, \mathrm{pHi}=7, \mathrm{~V}=0.005 \mathrm{~L}$, dosage $=2.0 \mathrm{~g} / \mathrm{L}$ ).

\begin{tabular}{|c|c|c|c|c|c|}
\hline \multicolumn{3}{|c|}{ Langmuir constants } & \multicolumn{3}{|c|}{ Freundlich constants } \\
\hline$q_{m} \quad(\mathrm{mg} / \mathrm{g})$ & $K_{L} \quad(\mathrm{~L} / \mathrm{mg})$ & $R^{2}$ & $k_{F} \quad(\mathrm{~L} / \mathrm{mg})$ & $N$ & $R^{2}$ \\
\hline 58.8 & 0.156 & 0.999 & 14.99 & 3.125 & 0.895 \\
\hline \multicolumn{3}{|c|}{ Temkin constants } & \multicolumn{3}{|c|}{ Dubinin-Radushkevich (D - R) constants } \\
\hline$b_{T} \quad(\mathrm{~kJ} / \mathrm{mol})$ & $k_{T} \quad(\mathrm{~L} / \mathrm{mg})$ & $R^{2}$ & $q_{s} \quad(\mathrm{mg} / \mathrm{g})$ & $B\left(\mathrm{~mol}^{2} / \mathrm{kJ}^{2}\right)$ & $R^{2}$ \\
\hline 0.236 & 2.24 & 0.962 & 44.345 & 2.220 & 0.953 \\
\hline
\end{tabular}


Table 3. Comparison of the maximum monolayer adsorption of CV dye onto various adsorbents.

\begin{tabular}{ccc}
\hline Adsorbent & $q_{m}$ (mg/g) & Reference \\
Bottom ash & 12.10 & {$[49]$} \\
TS, NaOH-TS & 118,195 & {$[50]$} \\
\hline Ananas comosus (pineapple) leaf powder (PLP) & 158.73 & {$[51]$} \\
Phosphoric acid activated carbons (PAAC) & 60.42 & {$[32]$} \\
Sulphuric acid activated carbons (SAAC) & 85.84 & {$[52]$} \\
Cocoa (theobroma cacao) shell (CSAC) & 43.50 & {$[53]$} \\
Activated carbon & $15.7-19.8$ & {$[22]$} \\
ZFA & 19.6 & {$[22]$} \\
ZBA & 17.6 & {$[48]$} \\
Tifferent natural materials & $60.8-65.8$ & present study \\
\hline
\end{tabular}

\section{Separation Factor and Surface Coverage $(\theta)$}

There are two factors such separation factor $\left(R_{L}\right)$, and surface coverage $(\theta)$ can help and give significant information about the behavior of the interaction between the adsorbent and the adsorbate. Separation factor is a dimensionless constant which can be used as a characteristic for Langmuir isotherm [44] as shown by the following equation:

$$
R_{L}=\frac{1}{1+K_{L} C_{0}}
$$

where $C_{0}(\mathrm{mg} / \mathrm{L})$ is the initial concentration of CV dye and $K_{L}(\mathrm{~L} / \mathrm{mg})$ is Langmuir constant. The value of $R_{L}$ indicates the shape of the isotherm to be either linear $\left(R_{L}=1\right)$, unfavorable $\left(R_{L}>1\right)$, favorable $\left(0<R_{L}<1\right)$, or irreversible $\left(R_{L}=0\right)$. Figure 13 representing the Plot of $R_{L}$ versus $C_{0}$ of CV dye at room temperature. It can be seen that the $R_{L}$ values were in the range of 0.04 to 0.14 , which is less than unity, indicating that the adsorption of CV onto TTC is a favorable process and thus TTC is a good adsorbent for CV dye. Recently T. Depci et al. [48] found similar results for the adsorption of CV onto activated carbon derived from Gölbaşı lignite.

In addition, the surface coverage $(\theta)$ of the adsorbent (TTC) is related to the initial concentration of CV dye $\left(C_{0}\right)$ as a Langmuir type equation as follow:

$$
\begin{gathered}
K_{L} C_{0}=\frac{\theta}{(1-\theta)} \\
\theta=\frac{K_{L} C_{0}}{\left(1-K_{L} C_{0}\right)}
\end{gathered}
$$

where $K_{L}$ is Langmuir constant (the adsorption coefficient), $C_{0}$ is the initial concentration of $\mathrm{CV}$ and $\theta$ is the surface coverage. The values of $\theta$ calculated according to Equation (11) and plotted against the values of initial concentrations $\left(C_{0}\right)$ as shown in Figure 13. The results show that the adsorption of CV onto TTC was very fast in the beginning and the surface coverage $(\theta)$ increases rapidly with the increase of initial concentration. Then $\theta$ increases slowly when the initial concentration exceeds $30 \mathrm{mg} / \mathrm{L}$ until $\theta$ value is close to 1.0. This results show that TTC will be very effective adsorbent in removing CV ions from aqueous solutions.

\subsubsection{Freundlich Isotherm}

The adsorption process takes place on a heterogeneous surface when the resulted data followed Freundlich isotherm model. Freundlich equations (linear and nonlinear) can be expressed as: 


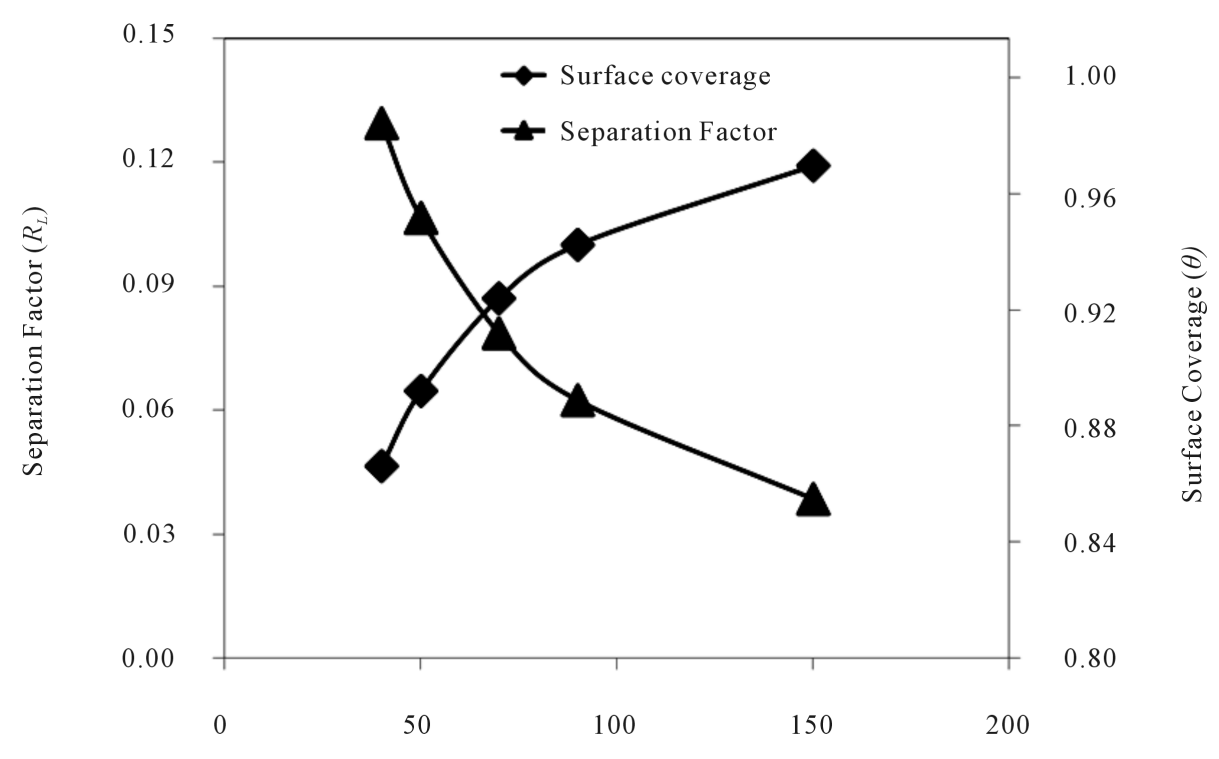

$[\mathrm{CV}]_{0}, \mathrm{mg} / \mathrm{L}$

Figure 13. Separation Factor $\left(R_{L}\right)$ and Surface Coverage $(\theta)$ for the adsorption of CV onto TTC $(\mathrm{T}=298 \mathrm{~K}$, time $=120 \mathrm{~min},[\mathrm{CV}] 0=40-150 \mathrm{mg} / \mathrm{L}, \mathrm{pHi}=7, \mathrm{~V}=0.005 \mathrm{~L}$, dosage $=2.0 \mathrm{~g} / \mathrm{L})$.

$$
\begin{aligned}
q_{e} & =K_{F} C^{1 / n} \\
\log q_{e} & =\log K_{F}+\frac{1}{n} \log C_{e}
\end{aligned}
$$

where $K_{F}(\mathrm{~L} / \mathrm{mg})$ is an indicator of the multilayer adsorption capacity and $\frac{1}{n}$ is the adsorption intensity and indicates both the relative distribution of energy and the heterogeneity of the adsorbent sites. Plot of $\log q_{e}$ versus $\log C_{e}$ at constant temperature is shown in Figure 12(b). The value of $K_{F}$ and $\frac{1}{n}$ (Table 2) was determined from the intercept and the slope respectively. Although, the value of $R^{2}(0.895)$ of Freundlich is lower than the value of $R^{2}$ (0.999) of Langmuir-I isotherm. This result indicates that Freundlich model is not a good model to describe the adsorption of CV dye onto TTC. The results of Langmuir and Freundlich implies that the adsorption of CVonto TTC show a mechanism involving only monolayer condition.

Recent reports for the adsorption of crystal violet dye onto different adsorbents found similar trends indicating that the equilibrium data were described well by Langmuir model and did not fit well with Freundlich model [54].

\subsubsection{Temkin Isotherms}

Equation (14) represented the linear form of Temkin isotherm model which can be used to test the adsorption potential of adsorbent to adsorbate. This equation supposes that increasing the coverage layer of adsorbate onto the surface of adsorbent makes the heat of adsorption $\left(\Delta H_{a d s}\right)$ of all molecules in that layer decreased linearly by increase the coverage.

$$
q_{e}=\frac{R T}{b_{T}} \ln K_{T}+\frac{R T}{b_{T}} \ln C_{e}
$$

where, $R$ is common gas constant $(0.008314 \mathrm{~kJ} / \mathrm{mol} \mathrm{K}), T$ is the absolute temperature $(\mathrm{K}), \frac{1}{b_{T}}$ is the Temkin constant related to the heat of sorption $(\mathrm{kJ} / \mathrm{mol})$ which indicates the adsorption potential (intensity) of the adsor- 
bent and $K_{T}(\mathrm{~L} / \mathrm{g})$ is Temkin constant related to adsorption capacity. The constants $\frac{1}{b_{T}}$ and $K_{T}$ can be calculated from the liner plots of $q_{e}$ versus $\ln C_{e}$ as shown in Figure 12(c). The numerical values of correlation coefficient $R^{2}$, in addition to both $K_{T}$ and $b_{T}$ of the Temkin equation for CV are represented in Table 2. Results indicate that the data of equilibrium isotherm of CVonto TTC $\left(R^{2}=0.971\right)$ are also can be described by the Temkin model. Also, the slight fitting of Temkin isotherm model for the adsorption of CV ions by Anethum graveolens was reported [18].

\subsubsection{Dubinin-Radushkevich (D-R) Isotherm Model}

The adsorption data of CV dye onto TTC were also tested by Dubinin-Raduskevich (D-R) isotherm model in order to investigate the characteristic porosity and the apparent free energy of adsorption. Isotherm model of D-R (Equation (15)) does not assume constant adsorption potential or homogeneous surface for the adsorbent [13].

$$
\ln q_{e}=\ln q_{m}-\beta \varepsilon^{2}
$$

where, $\beta$, a constant related to the mean free energy of adsorption ( $\left.\mathrm{mol}^{2} / \mathrm{J}\right)$ per molecule of $\mathrm{CV}$ dye (adsorbate) when transferred to the surface of TTC (adsorbent) from solution.

$q_{m}(\mathrm{mg} / \mathrm{g})$ is the theoretical saturation capacity based on D-R isotherm and $\varepsilon$ is the Polanyi potential (J/mol). $\varepsilon$ is related to the equilibrium concentration $C_{e},(\mathrm{mg} / \mathrm{L})$ and can be calculated from the following equation:

$$
\varepsilon=R T \ln \left(1+\frac{1}{C_{e}}\right)
$$

where $R$ is common gas constant $(8.314 \mathrm{~J} / \mathrm{mol} \mathrm{K})$ and $T(\mathrm{~K})$ is the absolute temperature. Figure $12(\mathrm{~d})$, representing the plot of $\ln q_{e}$ against $\varepsilon$ for adsorption of CV onto TTC which allows for the determining $q_{m}$ and $\beta$ from the intercept and the slope respectively. Table 2 shows the numerical values of $q_{m}$ and the correlation coefficient $\left(R^{2}\right)$. The high value of $R^{2}$ indicated that the adsorption of CV onto TTC followed D-R isotherm model. Based on the value of $\beta$, (which is related to the mean free energy of adsorption), the mean free energy of adsorption $(E)(\mathrm{KJ} / \mathrm{mol})$ can be calculated as follow:

$$
E=\frac{1}{\sqrt{2 \beta}}
$$

The results in Table 2 show that the value of $E$ is equal to $0.475 \mathrm{~kJ} / \mathrm{mol}$ which is lower than $8 \mathrm{~kJ} / \mathrm{mol}$. It indicates that the adsorption of CV dye onto TTC complex is a physical adsorption process. Similar results were obtained by T. Chinniagounder et al. [52] for the adsorption of CV dye onto Cocoa (Theobroma cacao) Shell Activated Carbon (CSAC).

\subsection{Standard Gibbs Free Energy Change $\left(\Delta G^{\circ}\right)$}

The degree of spontaneity of the adsorption process is mainly determined from standard Gibbs free energy $\left(\Delta G^{\circ}\right.$ ) equation. Increase the negative value of $\Delta G^{\circ}$ represents the increase in the spontaneity and the favorability of the adsorption [55]. Equations (18) and (19) were used to calculate $\Delta G^{\circ}$.

$$
\begin{gathered}
\Delta G^{o}=-R T \ln K_{C} \\
K_{C}=\frac{q_{e}}{C_{e}}
\end{gathered}
$$

where; $T$ is the temperature $(\mathrm{K}), R$ is gas constant $(\mathrm{kJ} / \mathrm{mol} \cdot \mathrm{K})$ and $K_{C}$ (dimensionless) is the standard thermodynamic equilibrium constant, hence both $q_{e}$ and $C_{e}$ are multiplied by the dosage of the adsorbent (g) used and is the amount of adsorbed CV per unit mass of TTC at equilibrium (mg/g) used and the volume (L) of the solution used. Calculation of $\Delta G^{\circ}$ from previous equation was more negative and the average $\Delta G^{\circ}$ was calculated as $(-18.12 \mathrm{~kJ} / \mathrm{mol})$ which indicated that the adsorption of CV onto TTC adsorbent is spontaneous and favorably. It was noted that the absolute values of both $\Delta G^{\circ}$ and $K_{C}$ (equilibrium constant) decrease with the in- 
crease with the initial concentration of Crystal violet dye. These results were similar to the recent report for the adsorption of CV dye onto activated carbon derived from Gölbaşı lignite [48].

\section{Conclusion}

The main conclusions of this investigation indicated that Ti-tannate complex (TTC) could be used as an effective adsorbent for the removal of CV dye from aqueous solution. Also, the adsorption of CV dye onto TTC powder was found to depend on the contact time and the initial concentration in addition to the dosage of TTC. Furthermore, the electrostatic interactions between CV and TTC surface controlled by the value of $\mathrm{pH}$ and the maximum removal were observed at $\mathrm{pH}$ 7. Kinetic study of adsorption process showed that pseudo-second order was the best model to describe the rate of removal of CV dye with the correlation coefficient $\left(R^{2}\right)$ of 0.999 . Also, the intraparticle diffusion was not the rate determining step. The study of adsorption isotherm resulted in fitting the data well to three different models (based on the values of $R^{2}$ ) in the following order as Langmuir-I > Temkin > D-R, while Freundlich equations were not suitable to describe the adsorption process. The monolayer maximum capacity of CV onto TTC is $58.8 \mathrm{mg} / \mathrm{g}$ as obtained from Langmuir model. The removal of CV by TTC was favorable, rapid and effective. Hence, the value of separation factor $\left(R_{L}\right)$ was less than unity and the value of surface coverage $(\theta)$ increased rapidly with the increase of $[\mathrm{CV}]_{0}$ till became close to 1.0. In addition, the adsorption of CV is spontaneous and physical process indicating that TTC is valuable adsorbent for removing $\mathrm{CV}$ from water and wastewater.

\section{Acknowledgements}

Author appreciated the great help and valuable discussion from Mr. Mohamed Hammad and Mr. Mahmoud Baseem, Al-Azhar University, Cairo, Egypt. Also, the author would like to thank Dr. El-Sayed Abd El-Monem Waly, Atomic Energy Authority, Egypt for great help in sample analysis.

\section{References}

[1] Grover V.I. (2006) Water: Global Common and Global Problems. Science Publisher, Enfield. http://dx.doi.org/10.1201/b11005

[2] Elmorsi, T.M., Mohamed, Z.H., Shopak, W. and Ismaiel A.M. (2014) Kinetic and Equilibrium Isotherms Studies of Adsorption of $\mathrm{Pb}(\mathrm{II})$ from Water onto Natural Adsorbent. Journal of Environmental Protection, 5, 1667-1681. http://dx.doi.org/10.4236/jep.2014.517157

[3] Bhattacharyya, K.G. and Sharma, A. (2004) Adsorption of Pb(II) from Aqueous Solution by Azadirachta indica (Neem) Leaf Powder. Journal of Hazardous Materials, B113, 97-109. http://dx.doi.org/10.1016/j.jhazmat.2004.05.034

[4] Sharma, P., Kaur, H., Sharma, M. and Sahore, V. (2011) A Review on Applicability of Naturally Available Adsorbents for the Removal of Hazardous Dyes from Aqueous Waste. Environmental Monitoring and Assessment, 183, 151-195. http://dx.doi.org/10.1007/s10661-011-1914-0

[5] Attia, A.A., Girgis, B.S. and Fathy, N.A. (2008) Removal of Methylene Blue by Carbons Derived from Peach Stones by $\mathrm{H}_{3} \mathrm{PO}_{4}$ Activation: Batch and Column Studies. Dyes and Pigment, 76, 282-289. http://dx.doi.org/10.1016/j.dyepig.2006.08.039

[6] Moyo, M. and Chikazaza, L. (2013) Bioremediation of Lead(II) from Polluted Wastewaters Employing Sulphuric Acid Treated Maize Tassel Biomass. American Journal of Analytical Chemistry, 4, 689-695. http://dx.doi.org/10.4236/ajac.2013.412083

[7] Fil, B.A., Yilmaz, M.T., Bayar, S. and Elkoca, M.T. (2014) Investigation of Adsorption of the Dyestuff Astrazon Red Violet 3RN (Basic Violet 16) on Montmorillonite Clay. Brazilian Journal of Chemical Engineering, 31, 171-182. http://dx.doi.org/10.1590/S0104-66322014000100016

[8] Man, L.W., Kumar, P., Teng, T.T. and Wasewar, K.L. (2012) Design of Experiments for Malachite Green Dye Removal from Wastewater Using Thermolysis-Coagulation-Flocculation. Desalination and Water Treatment, 40, 260 271. http://dx.doi.org/10.1080/19443994.2012.671257

[9] van Leeuwen, J., Sridhar, A., Esplugas, M., Onuki, S., Cai, L. and Koziel, J.A. (2009) Ozonation within an Activated Sludge System for Azo Dye Removal by Partial Oxidation and Biodegradation. Ozone: Science \& Engineering, 31, 279-286. http://dx.doi.org/10.1080/01919510902907720

[10] Aoudj, S., Khelifa, A., Drouiche, N., Hecini, M. and Hamitouche, H. (2010) Electrocoagulation Process Applied to Wastewater Containing Dyes from Textile Industry. Chemical Engineering and Processing: Process Intensification, 49, 
1176-1182. http://dx.doi.org/10.1016/j.cep.2010.08.019

[11] Rondón, W., Freire, D., de Benzo, Z., Sifontes, A.B., González, Y., Valero, M. and Brito, J.L. (2013) Application of 3A Zeolite Prepared from Venezuelan Kaolin for Removal of Pb(II) from Wastewater and Its Determination by Flame Atomic Absorption Spectrometry. American Journal of Analytical Chemistry, 4, 584-593. http://dx.doi.org/10.4236/ajac.2013.410069

[12] Elmorsi, T.M., Riyad, Y.M., Mohamed, Z.H. and Abd El Bary, H.M. (2010) Decolorization of Mordant Red 73 Azo Dye in Water Using $\mathrm{H}_{2} \mathrm{O}_{2} / \mathrm{UV}$ and Photo-Fenton Treatment. Journal of Hazardous Materials, 174, 352-358. http://dx.doi.org/10.1016/j.jhazmat.2009.09.057

[13] Kan, T.T., Jiang, X.H., Zhou, L.M., Yang, M., Duan, M., Liu, P.L. and Jiang, X.M. (2011) Removal of Methyl Orange from Aqueous Solutions Using a Bentonite Modified with a New Gemini Surfactant. Applied Clay Science, 54, 184187. http://dx.doi.org/10.1016/j.clay.2011.07.009

[14] Fungaro, D.A. and Magdalena, C.P. (2012) Adsorption of Reactive Red 198 from Aqueous Solution by Organozeolite from Fly Ash: Kinetic and Equilibrium Studies. International Journal of Chemical and Environmental Engineering Systems, 3, 74-83.

[15] Mittal, A., Mittal, J., Malviya, A., Kaur, D. and Gupta, V.K. (2010) Adsorption of Hazardous Dye Crystal Violet from Wastewater by Waste Materials. Journal of Colloid and Interface Science, 343, 463-473.

[16] Chakraborty, S., Chowdhury, S. and Saha, P.D. (2011) Adsorption of Crystal Violet from Aqueous Solution onto NaOH-Modified Rice Husk. Carbohydrate Polymers, 86, 1533-1541. http://dx.doi.org/10.1016/j.carbpol.2011.06.058

[17] Pei, Y.Y., Wang, M., Tian, D., Xu, X.F. and Yuan, L.J. (2015) Synthesis of Core-Shell SiO ${ }_{2} @ M$ O with Flower like Morphology for Removal of Crystal Violet in Water. Journal of Colloid and Interface Science, 453, 194-201. http://dx.doi.org/10.1016/j.jcis.2015.05.003

[18] Kyzas, G.Z. and Kostoglou, M. (2014) Green Adsorbents for Wastewaters: A Critical Review. Materials, 7, $333-364$. http://dx.doi.org/10.3390/ma7010333

[19] Blackburn, R.S. (2004) Natural Polysaccharides and Their Interactions with Dye Molecules: Applications in Effluent Treatment. Environmental Science and Technology, 38, 4905-4909. http://dx.doi.org/10.1021/es049972n

[20] Fry, B.A. (1957) Basic Triphenylmethane Dyes and the Inhibition of Glutamine Synthesis by Staphylococcus uureus. Journal of General Microbiology Society, 16, 341-349.

[21] Ayed, L., Chaieb, K., Cheref, A. and Bakhrouf, A. (2009) Biodegradation of Triphenylmethane Dye MG by Sphingomonas paucimobilis. World Journal of Microbiology and Biotechnology, 25, 705-711. http://dx.doi.org/10.1007/s11274-008-9941-X

[22] Bertolini, T.C.R., Izidoro, J.C., Magdalena, C.P. and Fungaro, D.A. (2013) Adsorption of Crystal Violet Dye from Aqueous Solution onto Zeolites from Coal Fly and Bottom Ashes. Orbital-The Electronic Journal of Chemistry, 5, 179-191.

[23] Zhang, R.N., Li, L. and Liu, J.X. (2015) Synthesis and Characterization of Ferric Tannate as a Novel Porous Adsorptive-Catalyst for Nitrogen Removal from Wastewater. Advances-Royal Society of Chemistry, 5, 40785-40791.

[24] Hashem, A. and El-Khiraigy, K. (2013) Bioadsorption of Pb(II) onto Anethum graveolens from Contaminated Wastewater: Equilibrium and Kinetic Studies. Journal of Environmental Protection, 4, 108-119. http://dx.doi.org/10.4236/jep.2013.41012

[25] Miah, M.Y., Volchek, K., Kuang, W. and Tezel, F.H. (2010) Kinetic and Equilibrium Studies of Cesium Adsorption on Ceiling Tiles from Aqueous Solutions. Journal of Hazardous Materials, 183, 712-717. http://dx.doi.org/10.1016/j.jhazmat.2010.07.084

[26] Qiu, H., Lv, L., Pan, B.-C., Zhang, Q.-J., Zhang, W.-M. and Zhang, Q.-X. (2009) Critical Review in Adsorption Kinetic Models. Journal of Zhejiang University Science A, 10, 716-724. http://dx.doi.org/10.1631/jzus.A0820524

[27] Ho, Y.S. and McKay, G. (1999) Pseudo-Second Order Model for Sorption Processes. Process Biochemistry, 34, 735742. http://dx.doi.org/10.1016/S0032-9592(98)00112-5

[28] Hameed, B.H., Din, A.T.M. and Ahmad, A.L. (2009) A Novel Agricultural Waste Adsorbent for the Removal of Cationic Dye from Aqueous Solutions. Journal of Hazardous Materials, 162, 305-311. http://dx.doi.org/10.1016/j.jhazmat.2008.05.036

[29] Priyantha, N. and Bandaranayaka, A. (2011) Investigation of Kinetics of Cr(VI)-Fired Brick Clay Interaction. Journal of Hazardous Materials, 188, 193-197. http://dx.doi.org/10.1016/j.jhazmat.2011.01.090

[30] Li, W., Zhang, L., Peng, J., Li, N., Zhang, S. and Guo, S. (2008) Tobacco Stems as a Low Cost Adsorbent for the Removal of $\mathrm{Pb}(\mathrm{II})$ from Wastewater: Equilibrium and Kinetic Studies. Industrial Crops and Products, 28, 294-302. http://dx.doi.org/10.1016/j.indcrop.2008.03.007

[31] Boamah, P.O., Zhang, Q., Hua, M., Huang, Y., Liu, Y., Wang, W. and Liu, Y. (2014) Lead Removal onto Cross- 
Linked Low Molecular Weight Chitosan Pyruvic Acid Derivatives. Carbohydrate Polymers, 110, 518-527. http://dx.doi.org/10.1016/j.carbpol.2014.03.034

[32] Feng, N.C., Guo, X.Y., Liang, S., Zhu, Y.S. and Liu, J.P. (2011) Biosorption of Heavy Metals from Aqueous Solutions by Chemically Modified Orange Peel. Journal of Hazardous Materials, 185, 49-54. http://dx.doi.org/10.1016/j.jhazmat.2010.08.114

[33] Singha, B., Naiya, T.K., Bhattacharya, A.K. and Das, S.K. (2011) Cr(VI) Ions Removal from Aqueous Solutions Using Natural Adsorbents-FTIR Studies. Journal of Environmental Protection, 2, 729-735. http://dx.doi.org/10.4236/jep.2011.26084

[34] Pahlavanzadeh, H., Keshtkar, A.R., Safdari, J. and Abadi, Z. (2010) Biosorption of Nickel(II) from Aqueous Solution by Brown Algae: Equilibrium, Dynamic and Thermodynamic Studies. Journal of Hazardous Materials, 175, 304-310. http://dx.doi.org/10.1016/j.jhazmat.2009.10.004

[35] Wang, Y., Lu, Y.F., Chen, R.Z., Ma, L., Jiang, Y. and Wang, H. (2014) Lead Ions Sorption from Waste Solution Using Aluminum Hydroxide Modified Diatomite. Journal of Environmental Protection, 5, 509-516. http://dx.doi.org/10.4236/jep.2014.56054

[36] Pokhrel, D. and Viraraghavan, T. (2008) Arsenic Removal from an Aqueous Solution by Modified A. niger Biomass: Batch Kinetic and Isotherm Studies. Journal of Hazardous Materials, 150, 818-825. http://dx.doi.org/10.1016/j.jhazmat.2007.05.041

[37] Pantoja-Castro, M.A. and González-Rodríguez, H. (2011) Study by Infrared Spectroscopy and Thermogravimetric Analysis of Tannins and Tannic Acid. Revista latinoamericana de química, 39, 108-112.

[38] Senthilkumaar, S., Varadarajan, P.R., Porkodi, K. and Subbhuraam, C.V. (2005) Adsorption of Methylene Blue onto Jute Fiber Carbon: Kinetics and Equilibrium Studies. Journal of Colloid and Interface Science, 284, 78-82. http://dx.doi.org/10.1016/j.jcis.2004.09.027

[39] Senthilkumaar, S., Kalaamani, P. and Subburaam, C.V. (2006) Liquid Phase Adsorption of Crystal Violet onto Activated Carbons Derived from Male Flowers of Coconut Tree. Journal of Hazardous Materials B, 136, 800-808. http://dx.doi.org/10.1016/j.jhazmat.2006.01.045

[40] Heidari, H.Y., Mehraban, Z. and Heikkinen, H. (2013) Selective Adsorption of Pb(II), Cd(II), and Ni(II) Ions from Aqueous Solution Using Chitosan-MAA Nanoparticles. International Journal of Biological Macromolecules, 61, 251263. http://dx.doi.org/10.1016/j.ijbiomac.2013.06.032

[41] Giraldo, L. and Moreno-Piraján, J.C. (2008) $\mathrm{Pb}^{2+}$ Adsorption from Aqueous Solutions on Activated Carbons Obtained from Lignocellulosic Residues. Brazilian Journal of Chemical Engineering, 25, 143-151.

[42] Shouman, M.A., Khedr, S.A. and Attia, A.A. (2012) Basic Dye Adsorption on Low Cost Biopolymer: Kinetic and Equilibrium Studies. IOSR Journal of Applied Chemistry (IOSR-JAC), 2, 27-36.

[43] George, Z.K. and Nikolaos, K.L. (2009) Reactive and Basic Dyes Removal by Sorption onto Chitosan Derivates. Journal of Colloid and Interface Science, 331, 32-39. http://dx.doi.org/10.1016/j.jcis.2008.11.003

[44] Elmorsi, T.M. (2011) Equilibrium Isotherms and Kinetic Studies of Removal of Methylene Blue Dye by Adsorption onto Miswak Leaves as a Natural Adsorbent. Journal of Environmental Protection, 2, 817-827. http://dx.doi.org/10.4236/jep.2011.26093

[45] Sahu, M.K., Mandal, S., Yadav, L.S., Dash, S.S. and Patel, R.K. (2015) Equilibrium and Kinetic Studies of Cd(II) Ion Adsorption from Aqueous Solution by Activated Red Mud. Desalination and Water Treatment, June 26, 1-15. http://dx.doi.org/10.1080/19443994.2015.1062428

[46] Manzoor, Q., Nadeem, R., Iqbal, M., Saeed, R. and Ansari, T.M. (2013) Organic Acids Pretreatment Effect on Rosa bourbonia Phyto-Biomass for Removal of $\mathrm{Pb}(\mathrm{II})$ and $\mathrm{Cu}(\mathrm{II})$ from Aqueous Media. Bioresource Technology, 132, 446452. http://dx.doi.org/10.1016/j.biortech.2013.01.156

[47] Ho, Y.-S. (2006) Review of Second-Order Models for Adsorption Systems. Journal of Hazardous Materials B, 136, 681-689.

[48] Patil, S., Deshmukh, V., Renukdas, S. and Patel, N. (2011) Kinetics of Adsorption of Crystal Violet from Aqueous Solutions Using Different Natural Materials. International Journal of Environmental Sciences, 1, 1116-1134.

[49] Gandhimathi, R., Ramesh, S.T., Sindhu, V. and Nidheesh, P.V. (2012) Single and Tertiary System Dye Removal from Aqueous Solution Using Bottom Ash: Kinetic and Isotherm Studies. Iranica Journal of Energy \& Environment, 3, 5262. http://dx.doi.org/10.5829/idosi.ijee.2012.03.01.0113

[50] Lim, L.B.L., Priyantha, N., Zehra, T., Then, C.W. and Chan, C.M. (2015) Adsorption of Crystal Violet Dye from Aqueous Solution onto Chemically Treated Artocarpus odoratissimus Skin: Equilibrium, Thermodynamics, and Kinetics Studies. Desalination and Water Treatment, 53, 1-15.

[51] Neupane, S., Ramesh, S.T., Gandhimathi, R. and Nidheesh, P.V. (2015) Pineapple Leaf (Ananas comosus) Powder as a 
Biosorbent for the Removal of Crystal Violet from Aqueous Solution. Desalination and Water Treatment, 54, 20412054. http://dx.doi.org/10.1080/19443994.2014.903867

[52] Chinniagounder, T., Shanker, M. and Nageswaran, S. (2011) Adsorptive Removal of Crystal Violet Dye Using Agricultural Waste Cocoa (Theobroma cacao) Shell. Research Journal of Chemical Sciences, 1, 38-45.

[53] Malarvizhi, R. and Ho, Y.-S. (2010) The Influence of pH and the Structure of the Dye Molecules on Adsorption Isotherm Modeling Using Activated Carbon. Desalination, 264, 97-101. http://dx.doi.org/10.1016/j.desal.2010.07.010

[54] Depci, T., Kul, A.R., Onal, Y., Isli, E.D., Alkan, S. and Turkmenoglu, Z.F. (2012) Adsorption of Crystal Violet from Aqueous Solution on Activated Carbon Derived from Gölbaşi Lignite. Physicochemical Problems of Mineral Processing, 48, 253-270.

[55] Jirekar, D.B., Pramila, G. and Farooqui, M. (2014) Kinetics and Isotherm Studies on Crystal Violet Dye Adsorption onto Black Gram Seed Husk. International Journal of ChemTech Research, 15, 427-434. 